\title{
UMA QUESTÃO DE DIREITO: SOBREPOSIÇÃO ENTRE PARQUES NACIONAIS E TERRAS INDÍGENAS INGARIKÓ, NUKINI E NAWA
}

\author{
ANA BEATRIZ LEÇA DE LIMA ${ }^{1}$ \\ UFSCar \\ CAMILA APARECIDA DA CRUZ ${ }^{2}$ \\ UFSCar \\ FERNANDA SOLA ${ }^{3}$ \\ UFSCAr
}

\begin{abstract}
RESUMO: O Sistema Nacional de Unidades de Conservação estabelece, entre outras providências, que toda área que se encontre nos limites da unidade de conservação classificada como parque nacional será desapropriado em favor do Estado. A presença humana nesses espaços tem gerado uma série de discussões, visto que cerca de 60 unidades de conservação se encontram sobrepostas a terras indígenas. Compõem esse número o Parque Nacional do Monte Roraima e a Terra Indígena Raposa Serra do Sol, em Roraima, bem como o Parque Nacional da Serra do Divisor e as terras indígenas Nukini e Nawa, no estado do Acre. Desta forma, este artigo pretende analisar tais sobreposições. Para fundamentação teórica, recorreu-se ao levantamento bibliográfico e as disposições legais pertinentes ao assunto. Muitas variáveis devem ser avaliadas quando se trata de sobreposições, no entanto, um caminho possivel seria a gestão compartilhada dessas áreas, permitindo a conservação da biodiversidade e da cultura local.
\end{abstract}

PALAVRAS-CHAVE: gestão compartilhada; proteção integral; sobreposição; terra indígena.

ABSTRACT: The National System of Conservation Units establishes, among other provisions, that all area that meets the national parks conservation units will be expropriated in favor of the state. The human presence in these spaces has generated a lot of discussions, since about 60 conservation units are superimposed to indigenous lands. Included in this number are the Monte Roraima National Park and the Raposa Serra do Sol Indigeouns Land, in Roraima, as

\footnotetext{
${ }^{1}$ Graduada em Licenciatura e Bacharelado em Ciências Biológicas - Universidade Federal de Uberlândia. Mestranda no Programa de Pós-Graduação em Sustentabilidade na Gestão Ambiental - Universidade Federal de São Carlos. E-mail: bia_leca@hotmail.com .

2 Graduada em Engenharia Ambiental - Universidade Federal de São Carlos. Especialização em andamento em Educação Ambiental para Sustentabilidade - SENAC/SP. Mestranda no Programa de PósGraduação em Sustentabilidade na Gestão Ambiental - Universidade Federal de São Carlos. E-mail: camilaac.ferreira@ hotmail.com .

${ }^{3}$ Phd em ciências ambientais, Universidade de São Paulo. Professora do PPGSGA, Universidade Federal de São Carlos E-mail: fernandasola@usp.br.
} 
well as the Serra do Divisor National Park and the Nukini and Nawa indigenous lands, in Acre. This article analyzes such overlaps. For theoretical basis, it was used literature and laws relevant to the point. Many variables must be evaluated when it comes to this kind of overlap, however, one possible way would be the shared management of these areas, allowing conservation of biodiversity and local culture.

KEYWORDS: shared management; overlap; integral protection; indigenous land.

\section{Tema geral}

Segundo a Lei 9.985 de 2000, que estabelece o Sistema Nacional de Unidades de Conservação (SNUC), uma unidade de conservação (UC) é caracterizada como:

Um espaço territorial e seus recursos ambientais, incluindo as águas jurisdicionais, com características naturais relevantes, legalmente instituído pelo Poder Público, com objetivos de conservação e limites definidos, sob regime especial de administração, ao qual se aplicam garantias adequadas de proteção (BRASIL, 2000, s/p).

Os objetivos expressos no SNUC visam colaborar para a preservação e a restauração da diversidade de ecossistemas naturais, bem como promover o desenvolvimento sustentável a partir do uso consciente dos recursos naturais, favorecer condições e promover a educação e interpretação ambiental, a recreação em contato com a natureza e o turismo ecológico, e proteger os recursos naturais necessários à subsistência de populações tradicionais, respeitando e valorizando seu conhecimento e sua cultura e promovendo-as no âmbito social e econômico (BRASIL, 2000).

No parágrafo anterior, os objetivos destacados explicitam que a participação e presença humana nesses espaços estão inteiramente ligadas aos aspectos ambientais. Considerando, ainda, o exposto no texto legal estabelecido pelo SNUC, são diretrizes norteadoras das UCs a participação efetiva das populações locais em sua criação, implantação e gestão. Desta forma, o Estado deverá promover meios que estimulem as populações locais e as organizações privadas a administrarem unidades 
de conservação em conjunto, de forma que seja garantido às populações tradicionais cuja subsistência dependa da utilização de recursos naturais existentes no interior dessas unidades meios de subsistência alternativos ou a justa indenização pelos recursos perdidos (BRASIL, 2000).

O texto do SNUC estabeleceu dois grandes grupos de UCs, tais grupos se diferenciam, basicamente, pelas restrições que envolvem cada unidade. Em um extremo encontram-se as UCs de proteção integral, locais onde não é permitido o uso direto dos recursos naturais, cujo objetivo principal é a preservação dos ecossistemas e o desenvolvimento da pesquisa científica, já a visitação é possível, desde que tenha caráter educativo. Fazem parte desse grupo as estações ecológicas, as reservas biológicas, os parques nacionais, monumentos naturais e refúgios da vida silvestre.

Em outro grupo, encontram-se as UCs de uso sustentável, que têm como principal característica a exploração sustentável das florestas nativas integrada à pesquisa científica. Outra característica importante desse grupo é a admissão da permanência de populações tradicionais no interior dos seus limites, com restrições. Compõem esse grupo a área de proteção ambiental, área de relevante interesse ecológico, floresta nacional, reserva extrativista, reserva de fauna, reserva de desenvolvimento sustentável e reserva particular do patrimônio natural (BRASIL, 2000).

Apesar da divisão das UCs nesses grandes grupos, é importante frisar que independente da categoria a ser criada, a legislação brasileira prevê que antes da criação de uma UC são necessários estudos técnicos e consultas públicas que permitam, entre outros aspectos, colher informações a respeito da população residente no local ou no entorno da área a ser transformada em unidade de conservação (BRASIL, 2000).

Outro aspecto importante expresso no SNUC é a questão das sobreposições. Acerca desse assunto a lei esclarece que havendo justaposição ou sobreposição de unidades de conservação, sejam elas da mesma categoria ou não, públicas ou privadas, a gestão deverá ser realizada de forma participativa e integrada. O objetivo principal dessa gestão participativa e integrada, além de conservar os objetivos de cada tipo de UC, é, sobretudo, favorecer e compatibilizar a conservação da 
biodiversidade e a da sociodiversidade (BRASIL, 2000).

Considerando uma situação em que não seja possível a permanência de populações tradicionais no interior da UC, a retirada dessas populações e o seu reassentamento deverão ser seguidos de uma indenização ou compensação. Contudo, durante o espaço de tempo que antecede tal reassentamento, o poder público viabilizará a participação da população tradicional na criação de normas e ações que compatibilizem sua presença com os objetivos da UC (BRASIL, 2002).

Ainda durante a criação de uma UC, devem ser analisadas as características naturais e as denominações mais antigas, como terras indígenas, conforme o previsto no Decreto 4.340 de 2002, que regulamenta alguns artigos da lei do SNUC (BRASIL, 2002).

Para tratar das questões envolvendo a população indígena, a legislação brasileira conta com os artigos 231 e 232 do capítulo VIII da Constituição federal de 1988. Esse capítulo reconhece aos índios seus costumes, organização, línguas e crenças, além de versar a respeito dos direitos sobre as terras que tradicionalmente são por eles ocupadas. Fica estabelecido, também, a partir desses artigos, que a responsabilidade pela demarcação, proteção e respeito a todos os bens desses povos é matéria da União (BRASIL, 1988).

Apesar do capítulo destinado aos povos indígenas contar apenas com dois artigos e alguns parágrafos, o seu conteúdo é bastante claro. Entre outras ponderações, esses artigos definem o que são consideradas terras indígenas, esclarecendo que, além da necessidade de serem ocupadas pelos índios em caráter permanente, elas devem favorecer 0 desenvolvimento de suas atividades produtivas, bem como a preservação dos recursos ambientais necessários ao seu bem-estar e a sua reprodução física e cultural, considerando suas formas de uso, seus costumes e tradições (BRASIL, 1988).

Ainda de acordo com o texto legal, a remoção dos grupos indígenas de suas terras é vedada, contudo, poderá ser considerada, em caso de catástrofe ou epidemia que coloque em risco a população indígena ou, ainda, em caso de interesse da soberania do país (BRASIL, 1988).

Sobre a questão da sobreposição envolvendo territórios indígenas e unidades de conservação, o Decreto 5.758 de 2006 prevê estratégias 
para gestão compartilhada entre unidades de conservação e terras indígenas (BRASIL, 2006).

\section{Problema de pesquisa}

A questão da sobreposição em áreas protegidas tem provocado inúmeras discussões, visto que a presença de populações tradicionais no interior de UCs gera os mais variados conflitos, que envolvem diversos interesses, incluindo o social, o econômico, o cultural, o ambiental, o preservacionista, dentre outros.

Quando uma área natural protegida é criada em territórios ocupados por populações tradicionais, as mesmas lidam com essa situação como sendo uma usurpação de seus direitos sagrados à terra onde viveram seus antepassados (DIEGUES, 2001).

O confronto entre a criação dessas áreas naturais protegidas para a conservação da natureza e a exclusão das famílias tradicionais configura-se em um confronto de dois saberes: o tradicional e o científico-moderno. Sendo que de um lado tem-se o conhecimento científico, originado das ciências exatas sem o conhecimento tradicional acumulado com os anos, e de outro lado tem-se esse saber acumulado sobre a terra, os ciclos naturais, a fauna e a flora, sistemas de manejo dos recursos naturais, os melhores períodos para certas atividades em certas áreas, entre outros conhecimentos (DIEGUES, 2001).

Esse confronto dos dois saberes, o saber e técnica tradicional e o saber da ciência, também se manifestam no momento da administração dos recursos naturais. Raramente o conhecimento tradicional e as técnicas de manejo patrimoniais são valorizados no momento de elaborar os planos de manejo das áreas naturais protegidas, até mesmo quando os grupos tradicionais ainda residem nessas áreas.

O autor Diegues (2001) relata que no Terceiro Congresso Mundial de Parques Nacionais, em 1962, em Bali (Indonésia), a problemática da relação entre as populações locais e as unidades de conservação foi mais aprofundada. Os direitos das sociedades tradicionais à determinação social, econômica, cultural e espiritual foram reafirmados e ainda foi aconselhado às autoridades responsáveis que o 
planejamento e manejo das áreas protegidas utilizassem as habilidades tradicionais das populações afetadas pelas medidas conservacionistas, e que as decisões para o manejo fossem conjuntas entre as sociedades que tradicionalmente manejavam os recursos naturais e os responsáveis pelas áreas protegidas, considerando a multiplicidade de circunstâncias locais.

A gestão integrada foi recomendada, porém sem reconhecer explicitamente a existência de populações locais dentro das áreas protegidas e os conflitos gerados com sua expulsão.

Cerca de vinte anos depois da ocorrência do referido congresso, em 1985, o debate sobre populações em parques estava ainda mais ampliada, o que fez com que a revista Cultural Survival (vol. 9, n. 1, fevereiro 1985) dedicasse um volume inteiro para a discussão do tema, sob o título: Parks and People. Logo de início, o editor da revista criticou a expulsão das famílias tradicionais de áreas protegidas e trouxe nessa mesma edição as atas da Primeira Conferência sobre Parques Culturais, que ocorreu no Parque Nacional de Mesa Grande, em 1984, evento onde foi reafirmado que os valores dos modos de vida tradicionais devem ser reconhecidos, e em casos de sobreposições, esses devem ser igualmente protegidos. Ainda nessa edição, novamente recomendou-se o envolvimento de moradores tradicionais nas fases de planejamento e administração das unidades de conservação, além de garantir a essas populações acesso aos recursos naturais das áreas em que vivem (DIEGUES, 2001).

Nessa conferência, constataram que a maior dificuldade encontrada nos parques é convencer a população local dos benefícios das áreas protegidas. Nesse caso, existe o Manual para Manejo de Áreas Protegidas nos Trópicos, que propõe medidas que permitem a essas populações a extração dos recursos naturais renováveis em caráter sazonal (MACKINNON et al., 1990).

Esse documento assegura que se pode sugerir a coleta manejada de certos recursos naturais pelas populações locais como forma de compensação pela perda de acesso a esses recursos (MACKINNON et al., 1990). E mostra a importância dos administradores das áreas protegidas em conquistar a população local, permitindo o uso sustentável e as práticas tradicionais e religiosas, porém sempre acompanhando e 
indicando alternativas com menores índices de impacto ambiental, gerando, assim, menos conflitos e garantindo a preservação dos recursos naturais.

Os problemas de sobreposição entre essas áreas não se resolvem apenas com desapropriação e indenizações às famílias tradicionais. É necessária a melhora nas condições de vida dessas pessoas, além de se recompensar pelo trabalho exercido em proveito da conservação da natureza, sendo que sem essas populações, muitos dos ecossistemas hoje transformados em unidades de conservação já teriam sido devastados (DIEGUES, 2001).

Segundo Diegues (2001):

Há grande necessidade de se conhecer melhor as relações entre a manutenção da diversidade biológica e a conservação da diversidade cultural. Quase nenhuma pesquisa sistemática foi realizada nesse sentido. Até hoje, no Brasil, a avaliação de uma área a ser declarada unidade de conservação tem sido responsabilidade única dos cientistas naturais. É necessária uma visão interdisciplinar, onde trabalhem de forma integrada biólogos, engenheiros florestais, sociólogos, antropólogos e cientistas políticos, entre outros, em cooperação com as populações tradicionais (DIEGUES, 2001, p. 95).

Esse pensamento do autor é cabível uma vez que a problemática da preservação da natureza por meio de áreas protegidas e a exclusão de populações tradicionais são discutidas somente por acadêmicos e autoridades políticas que conhecem pouco sobre o tema, e aqueles que conhecem de forma mais profunda como a natureza trabalha raramente são consultados e participam dos debates e decisões.

No Brasil é comum encontrar conflitos de sobreposição entre UC de proteção integral da categoria parque nacional e terras indígenas. De acordo com o SNUC, os parques nacionais têm como objetivo básico a preservação de ecossistemas naturais, permitindo a realização de pesquisas científicas e atividades de educação ambiental, de recreação e de turismo ecológico. Porém, por ser de posse e domínio público, toda e qualquer área particular incluída nos limites do parque poderão ser desapropriadas (BRASIL, 2000).

Já a definição de terras indígenas é dada pelo artigo 231 da 
Constituição federal. Em seu parágrafo segundo são apresentadas características importantes sobre esses locais: "as terras tradicionalmente ocupadas pelos índios destinam-se a sua posse permanente, cabendo-lhes o usufruto exclusivo das riquezas do solo, dos rios e dos lagos nelas existentes". Portanto, os indígenas têm a posse desses espaços, sendo que a sua propriedade permanece a cargo da União. Posse essa que é considerada legítima, desde que atenda aos requisitos legais estabelecidos pela própria Constituição, mesmo antes de sua demarcação, já que esse seria apenas um ato administrativo (FUNAI, 2016).

Logo, as terras indígenas descritas pelo artigo 231 são aquelas em que a presença dos povos indígenas é algo imemorial, ou seja, sempre contaram com ocupação tradicional, é justamente essa característica que as diferem das reservas indígenas, que são espaços que também visam o cuidado e conservação da cultura e o bem-estar dos indígenas, mas foram doadas por terceiros ou adquiridas pela União para essa finalidade (FUNAI, 2016).

A quantidade de sobreposições também é um dado que chama atenção, já que o Brasil conta com cerca de 70 casos, incluindo UCs, terras indígenas ( $\mathrm{Tl})$ e territórios de quilombolas (Figura 1). Considerando somente as sobreposições entre UCs e Tls, tem-se a ocupação de uma área de 8.853.013, 92 ha, sendo que o maior número de casos estão presentes na região da Amazônia Legal (ABIRACHED, BRASIL e SHIRAISHI, 2010).

A questão primordial envolvendo as terras indígenas e UCs é o fato de muitos especialistas acreditarem que a presença humana nesses espaços contribui para o aniquilamento da biodiversidade local. Contudo, diversos estudos demonstram que na realidade as comunidades tradicionais, e nestas estão inclusas os povos indígenas, contribuem para a manutenção e equilíbrio dos serviços ecossistêmicos. É evidente que tais comunidades, assim como as ditas não tradicionais, também sofrem alterações devido às pressões internas e externas, porém em um ritmo mais lento, isso aliado a sua dependência aos recursos naturais, seu sistema de manejo e seus rituais, colaboram intensamente para que, na verdade, eles sejam fortes aliados no processo de preservação da biodiversidade (MINISTÉRIO DO MEIO 
AMBIENTE, 1999).

Figura 1 - Mapa de sobreposições das áreas protegidas: unidades de conservação, terras indígenas, territórios quilombolas e assentamentos

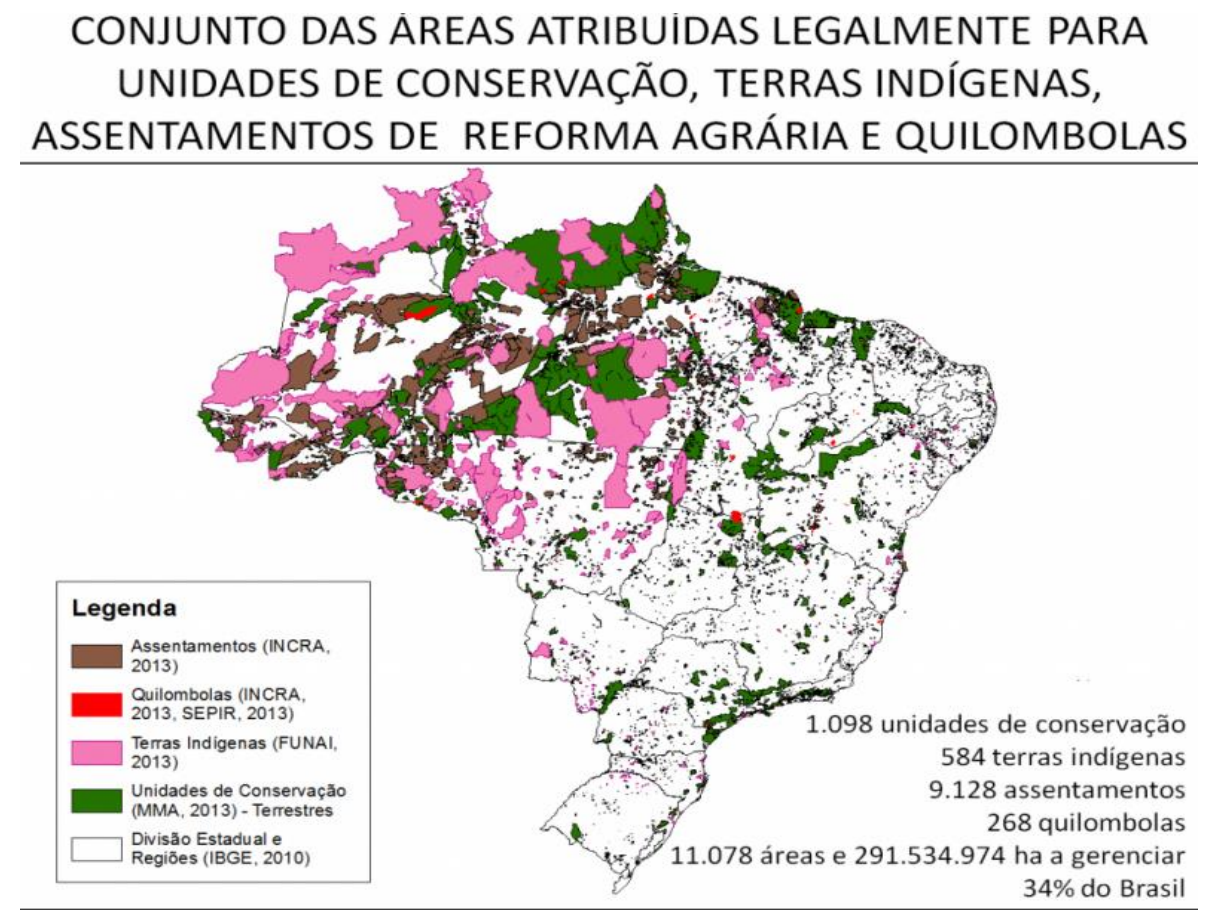

Fonte: www.embrapa.br/gite/projetos/alcance/index.html.

São exemplos desses conflitos o Parque Nacional do Monte Roraima e a Terra Indígena Raposa Serra do Sol, em Roraima, bem como o Parque Nacional da Serra do Divisor e as terras indígenas Nukini e Nawa, no estado do Acre. Nesses locais, é grande o desafio da demarcação das UCs e das Tls relacionadas às possibilidades de conservação dessas áreas.

\section{Objetivos}

- Objetivo Geral: Analisar a relação entre ocupação humana, mais especificadamente as ocupações indígenas, com os objetivos de uma UC de Proteção Integral.

- Objetivo Específico: Apresentar e compreender a questão da sobreposição de UCs e Tls usando como objeto de estudo os casos do Parque Nacional do Monte Roraima/Terra Indígena Raposa Serra do Sol e 
Parque Nacional da Serra do Divisor/Terras Indígenas Nukini e Nawa, localizados nos estados de Roraima e Acre respectivamente.

\section{Metodologia}

O estudo ocorreu por meio de revisão bibliográfica, análise de dados secundários, bem como disposições legais pertinentes sobre unidades de conservação de proteção integral e terras indígenas.

A fonte principal da pesquisa bibliográfica foi o estudo intitulado Terras Indígenas e Unidades de Conservação da Natureza: O desafio das sobreposições, lançado no ano de 2004 pelo Instituto Socioambiental (ISA). Com enfoque nos capítulos Os Ingarikó e o Monte Roraima e Os Nawa e Nukini e a Serra do Divisor.

Como complementação da pesquisa, recorreu-se a artigos científicos, dissertações e teses que apresentassem em seus títulos, resumos ou corpo textual as palavras-chave: Monte Roraima, Serra do Divisor, Terra Indígena Raposa Serra do Sol, Terra Indígena Nawa, Terra Indígena Nukini, sobreposição, unidades de conservação e parque nacional.

Para compor a base legal, utilizou-se:

- Constituição da República Federativa do Brasil de 1988.

- Lei 9.985 de 18 de julho de 2000. Regulamenta o art. 225, § 1o, incisos I, II, III e VII da Constituição Federal, institui o Sistema Nacional de Unidades de Conservação da Natureza e dá outras providências.

- Decreto 4.340, de 22 de agosto de 2002. Regulamenta artigos da Lei 9.985 , de 18 de julho de 2000, que dispõe sobre o Sistema Nacional de Unidades de Conservação da Natureza - SNUC, e dá outras providências.

- Decreto 5758, de 13 de abril de 2006. Institui o Plano Estratégico Nacional de Áreas Protegidas - PNAP, seus princípios, diretrizes, objetivos e estratégias, e dá outras providências.

- Decreto 97.839, de 16 de junho de 1989. Cria o Parque Nacional da Serra do Divisor. 
Parque Nacional Monte Roraima e a Terra Indígena Raposa Serra do Sol

\section{O Parque Nacional do Monte Roraima}

Criado em 1989, o Parque Nacional do Monte Roraima (PNMR) ilustra com frequência manchetes e reportagens especiais sobre o turismo que enfatizam as belezas e maravilhas naturais desse espaço. Localizado na cidade de Uiramutã e fazendo divisa com a Venezuela e a República Cooperativa da Guiana, o seu território de 116 mil hectares compõe, juntamente com outros espaços, a Amazônia Legal.

Com uma vegetação rica em diversidade biológica, suas terras são cobertas por porções de cerrado e componentes do bioma amazônico. Entre as espécies mais comuns estão as orquídeas, que se encontram em grande variedade, as bromélias e diversos tipos de palmeiras. Considerando a flora local, há, ainda, uma quantidade relevante de espécies endêmicas de beleza singular. Com relação à fauna local, entretanto, pouco se conhece, mas acredita-se que, devido à riqueza da vegetação no local, exista, consequentemente, uma gama interessante de espécies faunísticas (IBAMA, 1999).

Todos esses adjetivos colaboraram na fundamentação e justificativa para a criação do Parque Nacional do Monte Roraima, pertencente à categoria de unidades de conservação de proteção integral, o que exclui qualquer tipo de uso direto de suas terras e a presença constante de comunidades no interior de seus limites.

A criação do PNMR faz parte de ações em prol da biodiversidade que seguem a linha conservacionista pura, ou seja, a conservação da biodiversidade ocorrerá, apenas, se for deslocada do convívio com o homem. Nesta concepção o homem é visto, e entendido, como ser à parte do meio natural e, portanto, uma espécie invasora. Na legislação nacional a presença humana em parques nacionais é limitada ao turismo ecológico e à realização de pesquisas e atividades educativas; é importante frisar, contudo, que tais atividades ficam restritas a algumas porções do parque.

Dessa forma, tal modelo de área protegida não admite, inclusive, a presença no interior do parque de comunidades que tradicionalmente 
são conhecidas por habitarem esse local. Novamente o pressuposto que embasa essa política conservacionista é um só: o resultado da relação entre o homem e a natureza sempre acarretará em degradação (MINISTÉRIO DO MEIO AMBIENTE, 1999).

Esclarecidos os conceitos que alicerçam a base teórica da criação de unidades de conservação de proteção integral, podemos retornar às questões do Parque Nacional do Monte Roraima. No início do texto são destacadas as belezas cênicas do local e que infinitas vezes são usadas como chamativos para a divulgação do turismo na região, contudo, outro aspecto do PNMR vem se tornando notícia há anos: a sobreposição de terras indígenas e o território do Parque. E esse é o ponto crucial e primordial das discussões e reflexões que se desenharão nas próximas linhas desse trabalho.

\section{Os Ingarikó}

Algo como o "povo do ápice da montanha" ou "gente da floresta densa" são possíveis traduções para o nome indígena ingarikó, o que muito revela sobre essa nação. Pertencente à família linguística karib e autodenominados kapon, juntamente com as tribos Patamona e Akawaio, os Ingarikó são povos centenários que ocupam desde muito antes da chegada dos europeus a porção territorial hoje conhecida como o estado de Roraima. Além do Estado brasileiro, esse povo também está presente na Venezuela e na Republica Cooperativa da Guiana, onde, inclusive, contam com tribos mais numerosas que as localizadas em nossas terras (LAURIOLA, 2004; RUFINO, 2004).

A base alimentar dessa população é composto pela mandioca, batata, milho e, entre as frutas, há a predominância da banana, seguida pelo abacaxi, laranja e tangerina. Interessante frisar que as aldeias se organizam para que não produzam os mesmos alimentos, havendo, assim, uma troca de mantimentos entre eles. Ainda sobre a organização social dos Ingarikó, é relevante citar o ritual da aleluia, que é um ritual de passagem repleto de significados para esse povo.

As aldeias ingarikó localizam-se no nordeste do estado de Roraima, na Terra Indígena Raposa Serra do Sol (TIRSS), território que foi 
reconhecido oficialmente como Terra Indígena apenas em 2008, após a homologação de sua demarcação. Tal processo de homologação levou anos para ocorrer e acarretou em grandes confrontos, visto que uma parte da Terra Indígena Raposa Serra do Sol é composta pelo Parque Nacional do Monte Roraima, instalado em 1989, mesmo ano em que se deu início ao procedimento para demarcação das terras dos Ingarikó.

Em 1998, além da homologação do território indígena, foi acordado que a gestão da porção territorial onde estava localizada a sobreposição de unidades seria compartilhada entre o povo Ingarikó, o Instituto Chico Mendes de Conservação da Biodiversidade e a Fundação Nacional do Índio (Funai). O período que antecedeu a homologação do território indígena, entretanto, trouxe à tona uma discussão recorrente: a sobreposição entre unidades de conservação e terras indígenas.

O Parque Nacional do Monte Roraima e o Território Indígena Raposa Serra do Sol

Ao falar-se do Parque Nacional do Monte Roraima e do Território Indígena Raposa Serra do Sol estamos falando de histórias que aconteceram paralelamente e com o mesmo cenário (Figura 2). O Parque foi criado em 1989, mesmo ano em que a Terra Indígena deu início ao seu processo de demarcação. Desse período até 2008 muitas foram as discussões sobre o pertencimento desse espaço. Durante anos a existência do Parque foi renegada pelos indígenas, assim como a demarcação da TIRSS não era considerada pelo órgão ambiental.

De acordo com Scardua (2004), a implantação do Parque através de seu plano de manejo foi realizada, em um primeiro momento, sem a efetiva participação da comunidade ingarikó. Do decreto que estabeleceu a criação do Parque, em 1989, até o primeiro plano de manejo, em 1999, os indígenas permaneceram em seu território sem saber da existência de uma unidade de conservação de proteção integral em seu limite e, principalmente, sem entender quais seriam as reais implicações dessa sobreposição em seus hábitos e costumes. 
Figura 2 - Parque Nacional do Monte Roraima e a Terra Indígena Raposa Serra do Sol.

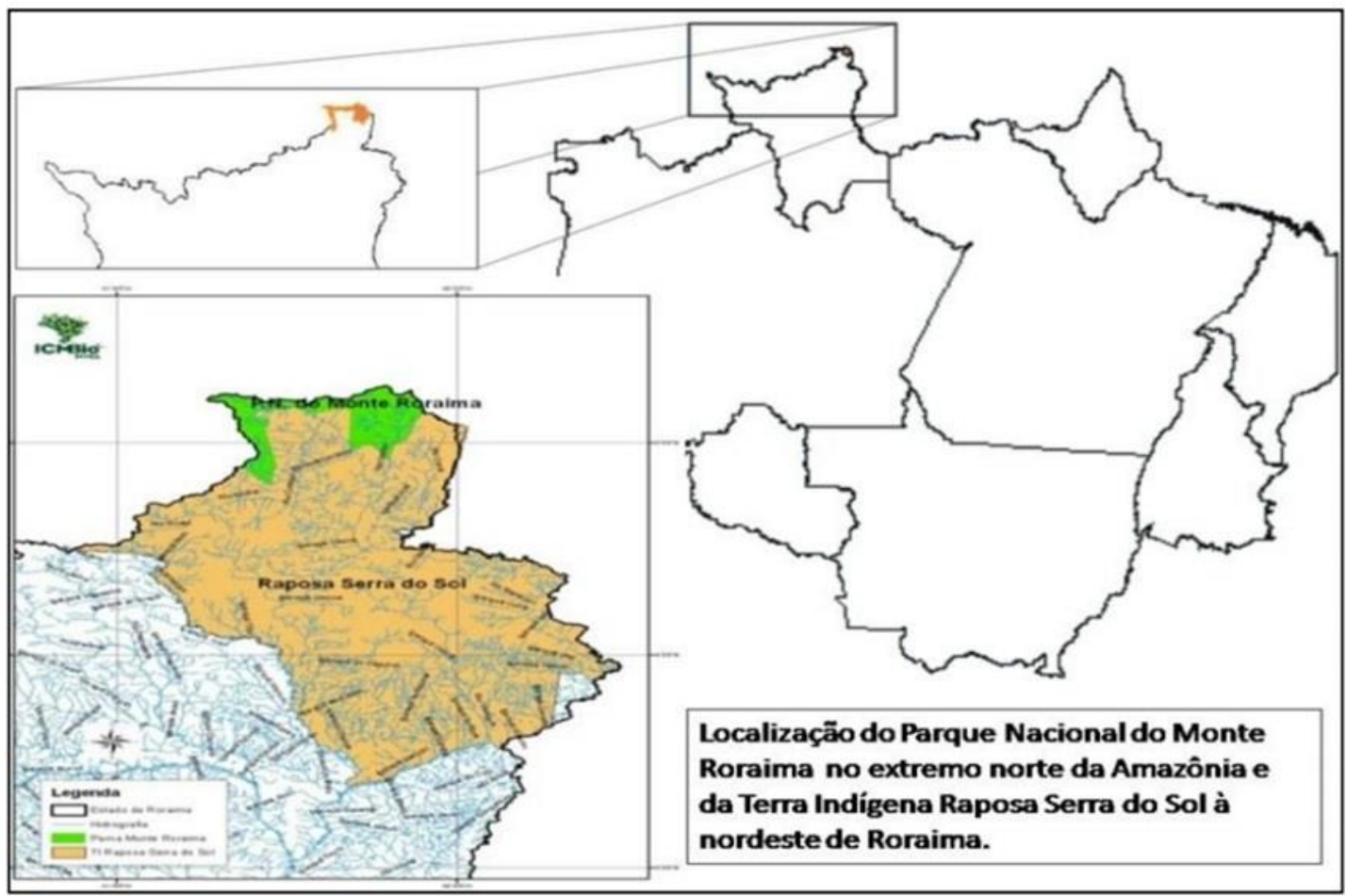

Fonte: ICMBIO (2015).

Um relato realizado pelos autores Scardua (2004), Lauriola (2004) e Rufino (2004) sugeria como possíveis soluções para essa situação de sobreposição que os conhecimentos dos indígenas fossem considerados e que houvesse uma gestão compartilhada da área. $\mathrm{E}$, fundamentalmente, que o zoneamento considerasse a organização social dos Ingarikó, dessa maneira a conservação seria abordada a partir das perspectivas culturais dos próprios índios, com ênfase no seu relacionamento com a natureza.

Em 2008, juntamente com a homologação da Terra Indígena Raposa Serra do Sol, foi também estabelecida a gestão participativa do Parque Nacional do Monte Roraima, contudo, apenas em 2012 foram realizadas as posses dos 8 membros do povo Ingarikó para o Conselho Gestor do Parque.

A solução apresentada acima demonstra que a melhor alternativa, tardia ou não, é o diálogo entre os povos. É necessário ouvir o que os indígenas têm a falar. Eles devem ser consultados e devem ter voz ativa nas questões que envolvam os seus territórios. Contudo, é importante 
frisar que essa participação não pode ser meramente ilustrativa, ou para cumprir qualquer tipo de protocolo; há a clara necessidade de se criar mecanismos em que a participação dos povos indígenas em discussões que os envolvam ocorra efetivamente e que seus anseios sejam considerados. E esse deve ser um ponto crucial e inicial das discussões sobre sobreposições, seja com a nação ingarikó ou com qualquer outra nação indígena.

\section{Parque Nacional da Serra do Divisor e as Terras Indígenas Nawa e Nukini}

Região do Alto Juruá

O Vale do Alto Rio Juruá está localizado no extremo oeste do Acre e faz parte de uma área de transição entre o Brasil e o Peru (CORREIA, 2004 e 2007). É delimitada pelas bacias Envira, Tarauacá, alto curso do Juruá e a Serra do Moa (BARNES, 2004 e 2006), e engloba os municípios de Cruzeiro do Sul, Feijó, Jordão, Mâncio Lima, Marechal Thaumaturgo, Porto Walter, Rodrigues Alves e Taraucá (IBAMA, 1998).

Povoada por grupos indígenas das famílias linguísticas pano, aruak e arawá e composta por matas tropicais e seringais com grandes potenciais para madeira e borracha (BARNES, 2004, 2006; CORREIA, 2004 e 2007), a região do Alto Juruá sofreu invasões de exploradores brasileiros e peruanos (CORREIA, 2004 e 2007; RODRIGUES, 2006).

Em meados da segunda metade do século XIX, nordestinos e peruanos invadiram essa região a procura de borracha e caucho, respectivamente. Além desses invasores, comerciantes de Belém e Manaus também usavam o curso do Rio Juruá para trocar bens industrializados por produtos florestais com a população nativa (CORREIA, 2004 e 2007; RODRIGUES, 2006).

Nesse período, os indígenas foram extremamente prejudicados na disputa de terras com os comerciantes. A ocupação desses exploradores gerou as corridas (agarramentos) e descimentos dos povos indígenas e momentos marcados por força e violência (BARNES, 2004 e 2006; RODRIGUES, 2006). Como resultado, a maioria da população indígena da região foi dizimada, escravizada, dispersa ou incorporada na empresa 
seringalista (BARNES, 2004 e 2006; CORREIA, 2004 e 2007; RODRIGUES, 2006).

Contudo, no ano de 1912, com a queda do preço da borracha no mercado internacional e as reformas econômicas, as batalhas entre os comerciantes e povos indígenas diminuíram sensivelmente (RODRIGUES, 2006).

Mais adiante, em 1970, diversos programas de apoio à economia internacional e nacional nas regiões amazônicas foram implantados pelos militares. Dentre esses programas, pode-se destacar a abertura de estradas, como a BR-364 e a BR-163, que facilitaram a conexão com outros mercados (RODRIGUES, 2006).

Seguindo a cronologia, tem-se que no ano de 1989 , com o intuito de conservar a biodiversidade da região, e, principalmente, as diferentes espécies endêmicas e espécies ameaçadas de extinção, ocorreu a criação do Parque Nacional da Serra do Divisor (PNSD) (VELÁSQUEZ e GARCIA, 2004).

Devido a sua importância ambiental, o Parque recebeu auxílios internacionais para o seu processo de gestão ambiental e elaboração do plano de manejo (VELÁSQUEZ e GARCIA, 2004).

No início das atividades do Parque, a equipe de gestão focava unicamente em ações preservacionistas e tinha como estratégia afastar qualquer ação e presença humana que pudesse ser considerada um perigo à preservação da biodiversidade do local (VELÁSQUEZ e GARCIA, 2004; CORREIA, 2004 e 2007). Porém, essa forma de gestão, em que há o total distanciamento entre o meio natural e o social, vem sendo repensada ano após ano.

Parque Nacional da Serra do Divisor (PNSD)

O PNSD é uma unidade de conservação de proteção integral e foi criado em 16 de junho de 1989 pelo Decreto 97.839. Entretanto, somente em 1998 o plano de manejo foi elaborado pelo Instituto Brasileiro do Meio Ambiente e dos Recursos Naturais Renováveis (Ibama) com apoio da instituição ambientalista SOS Amazônia (BARNES, 2004 e 2006). 
Situado na região amazônica do Alto Juruá, o PNSD possui uma área de $843.012,28$ ha e é considerado como marco divisor entre as bacias do Rio Ucayali (Peru) e do Rio Juruá (Brasil) (IBAMA, 1998; VELÁSQUEZ e GARCIA, 2004).

O PNSD faz, ainda, parte da microrregião conhecida como Cruzeiro do Sul, e abrange áreas de cinco municípios, são eles: Cruzeiro do Sul, Mâncio Lima, Rodrigues Alves, Marechal Thaumaturgo e Porto Walter (IBAMA, 1998; BARNES, 2004 e 2006; CORREIA, 2004 e 2007; RODRIGUES, 2006).

No momento de criação do Parque, havia quatro etnias ao entorno de sua área, sendo elas Nukini, Ashaninka, Poyanawa e Arara. Porém, em 1999, outra etnia, denominada Nawa, reivindicou o reconhecimento de identidade indígena, esse povo encontrava-se na porção ao norte do interior do PNSD. Além da existência dessas etnias, estavam presentes nos limites e entornos do Parque 72 propriedades registradas como fazendas e seringais (VELÁSQUEZ e GARCIA, 2004).

As famílias que se encontram no interior do Parque somam um total de 522 unidades familiares, o que resulta em um número próximo a 3.115 pessoas. Em seu entorno imediato estão situadas, ainda, 996 famílias, totalizando 5.967 pessoas (IBAMA, 1998; BARNES 2004 e 2006). É necessário frisar que todas essas famílias dependem dos recursos naturais para sua sobrevivência. Além disso, desenvolvem atividades econômicas como agricultura de subsistência, seringa, criação, pesca, caça comercial e extrativismos de produtos florestais, dentre outras atividades que são consideradas ilegais e incompatíveis com os objetivos de um parque nacional (IBAMA, 1998).

De acordo com o artigo 11 , parágrafo $1^{\circ}$, da Lei $9.985 / 2000$, as áreas particulares que ocorrem dentro dos limites do parque nacional deverão ser desapropriadas (BRASIL, 2000). Logo, os conflitos territoriais e socioambientais constantes são esperados (CORREIA, 2004 e 2007).

Apesar do número vultoso de indivíduos vivendo dentro ou ao redor do Parque, durante os estudos e levantamentos para elaboração do seu plano de manejo, não houve a consulta com os seringueiros, proprietários de terra, criadores de gados e/ou povos indígenas. Além disso, o momento de comunicação com os moradores sobre a criação 
do Parque foi marcada por autoritarismo, uma vez que o Ibama não permitiu uma discussão sobre os direitos básicos de indenização e reassentamento. As populações não tiveram nem mesmo oportunidade de participarem e se representarem na produção das normas e sua execução (BARNES, 2004 e 2006).

Entretanto, não é apenas a ocupação humana que é um problema para a gestão do PNSD. Uma vez situado em região de fronteira entre Peru e Brasil, o Parque sofre constantes ameaças com extração irregular de madeira, grilagem de terra, tráfico de drogas, desmatamento, agricultura, pecuária, caça e pesca, comércio de peles, dentre outros. Toda essa problemática está diretamente relacionada com a falta de fiscalização e carência de atenção de outros órgãos (IBAMA, 1998; VELÁSQUEZ e GARCIA, 2004).

As fiscalizações no interior do parque ocorrem esporadicamente e apenas em resposta às denuncias de atividades ilegais e conflitantes (IBAMA, 1998). Está claro, porém, que a fiscalização deveria ocorrer constantemente, independente de qualquer denúncia, como forma de prevenção a essas ilegalidades.

O PNSD conta também com um Conselho Consultivo (CC PNSD) que foi criado em 2002 pela portaria 78 do Ibama. A priori, o CC PNSD era composto por 17 organizações governamentais, 11 não governamentais e nove representações das "comunidades" (BARNES, 2004 e 2006).

Um ano antes da criação do Conselho, foram realizados seminários com objetivo de divulgar e explicar sobre o CC PNSD a toda população e também eleger os conselheiros. Dessa forma, ficou estabelecido que a estrutura organizacional fosse composta por presidência, vice-presidência, secretaria executiva e uma plenária (BARNES, 2004 e 2006).

Ao decorrer das reuniões ordinárias e oficinas de capacitação, 32 organizações estiveram presentes. Dentre as cinco organizações ausentes, encontra-se a Funai, que não participou de nenhum evento (BARNES, 2004 e 2006).

Até 2004, o CC PNSD tinha apresentado três propostas para minimizar os conflitos territoriais: reduzir a área do PNSD, restringindoo apenas às áreas não habitadas; mudar a categoria da UC nas áreas 
habitadas e/ou transformar parte da área norte em terra indígena para os Nawa e Nukini (BARNES, 2004 e 2006).

Sobreposição da Terra Indígena Nukini e Terra Indígena Nawa no PNSD

Pertencentes da família linguística pano, os Nukini encontram-se em sua maioria na margem esquerda do Rio Môa, no município de Mâncio Lima, no estado do Acre. Até 2010, na TI Nukini habitavam cerca de 620 indígenas (VELÁSQUEZ e GARCIA, 2004; OLIVEIRA, MARTINI e LESSIN, 2012).

Em meados de 1970, a Funai iniciou o reconhecimento dessa terra indígena, que está localizada na zona de transição ao norte do PNSD (FIGURA 3). Em 1991 ocorreu a demarcação desse território, que foi homologado com um total de $27.263,81$ ha. Contudo, desde os anos 2000, os Nukini reivindicam o aumento de suas terras, o que faria com que esse povo adentrasse na área norte do PNSD (VELÁSQUEZ e GARCIA, 2004; BARNES, 2004 e 2006; CORREIA, 2004 e 2007).

Com relação aos povos Nawa, devido o massacre no final do século XIX, ocuparam a região do Rio Môa, e como estratégias para não sofrerem novos ataques e conflitos, deixaram de se identificar como povos indígenas. Ao longo de 30 anos, esse grupo indígena parou de ser mencionado nas fontes historiográficas e foram considerados extintos (CORREIA, 2004 e 2007).

Entretanto, em 1999, após a criação do PNSD, esses povos reapareceram com cerca de 300 pessoas. Eles reivindicavam reconhecimento à identidade indígena e demarcação de sua terra. (VELÁSQUEZ e GARCIA, 2004; CORREIA, 2004 e 2007).

Os limites da Terra Indígena Nawa sobrepõem parte da área norte do PNSD, o que gerou diversos estudos e relatórios de etnicidade desse povo (CORREIA, 2004 e 2007).

Com essas duas reivindicações por território, a gestão do PNSD e seu conselho consultivo estudaram algumas estratégias para minimizar esses conflitos até que seja resolvido (BARNES, 2004 e 2006). 
Figura 3 - Delimitação do Parque Nacional da Serra do Divisor em amarelo e as terras indígenas em vermelho, especificadamente a Terra Indígena Nukini, ao norte do PNSD

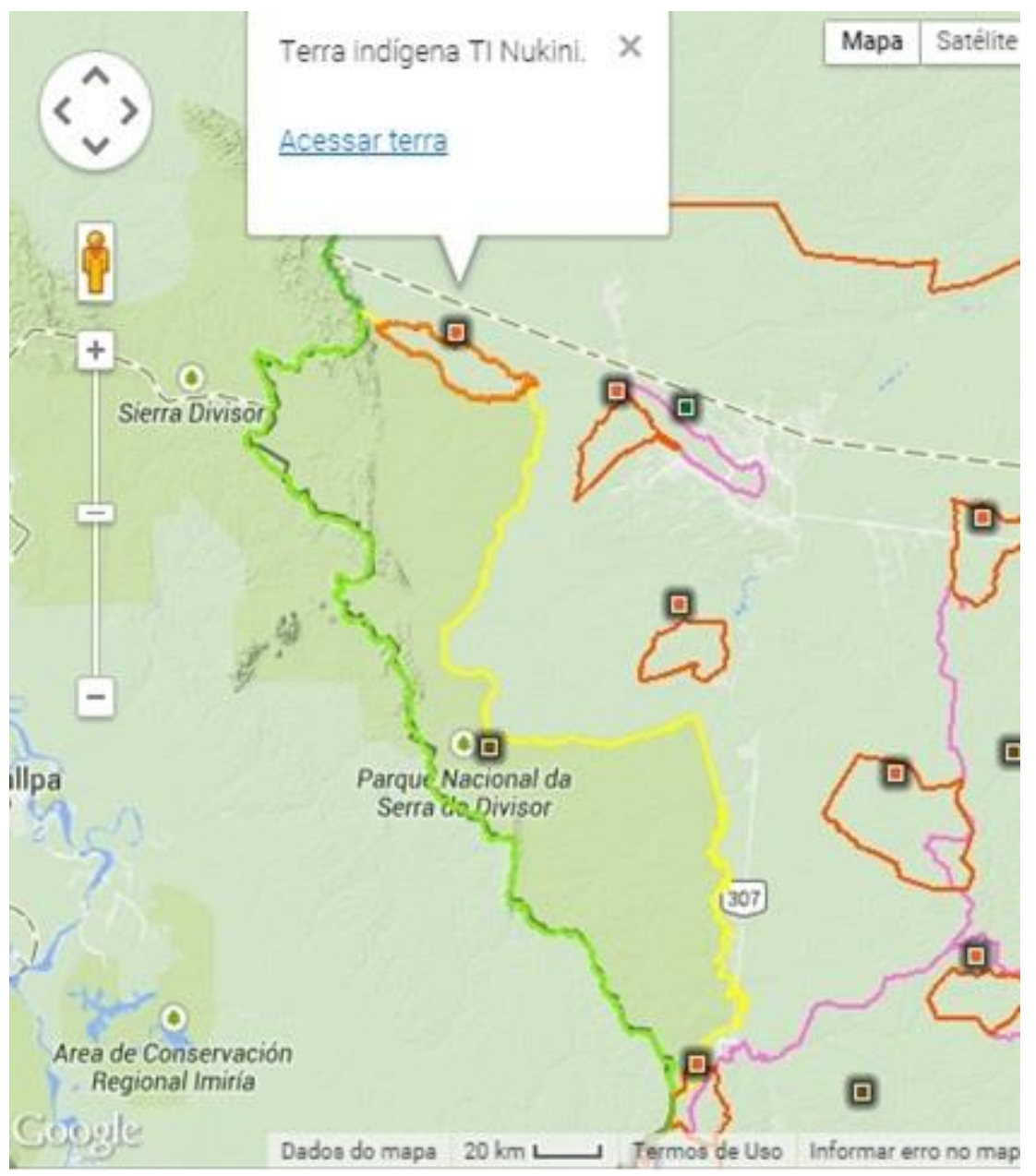

Fonte: http://pib.socioambiental.org/pt/povo/nukini/824.

Em relação à TI Nukini, o CC PNSD tentou convencê-los a reivindicarem expansão de suas terras para o norte, logo, fora da área do PNSD. Porém, muitos dos Nukini querem as terras dentro do Parque, por serem localizadas no "pé da Serra" (BARNES, 2004 e 2006).

O CC PNSD aguardava a decisão judicial sobre o reconhecimento e marcação da TI Nawa para posteriormente encontrar alguma possível solução para a sobreposição de tais terras (BARNES, 2004 e 2006).

No ano de 2003 firmou-se um acordo, envolvendo Ministério Público Federal, União, Funai, Ibama e representantes do povo Nawa. Nesse acordo foi reconhecia a etnia desse povo indígena e aceito os limites da TI sobre a área do PNSD. Porém, ficou estabelecido que seria necessária a elaboração de um plano de manejo específico e exclusivo 
para a TI Nawa, além de se permitir a realização de pesquisas científicas nesse local (BARNES, 2004 e 2006).

Outras questões que também necessitavam de uma solução urgente eram aquelas envolvendo as demais famílias que habitavam o interior do Parque. Para isso, em 1990 iniciou-se uma proposta de transferência de parte dessas famílias para o assentamento Gleba São Salvador, do Instituto Nacional de Colonização e Reforma Agrária (Incra), localizada no município de Mâncio Lima (BARNES, 2004 e 2006).

Após alguns estudos feitos pelo Grupo de Pesquisa e Extensão em Sistemas Agroflorestal do Acre (Pesacre), encontrou-se uma barreira posta pelos moradores da gleba, que não aceitavam a chegada de outras famílias, uma vez que já sofriam com a incapacidade de suporte da área e com conflitos sociais (BARNES, 2004 e 2006).

Essa barreira fez com que o CC PNSD apresentasse outra proposta de reassentamento dessas famílias do interior do Parque. Essa segunda proposta estava voltada para a Gleba Havaí, localizada no município de Rodrigues Alves. Mas os moradores do interior do Parque alegaram que, caso aceitassem a proposta, haveria uma perda significativa na qualidade de vida, uma vez que essa gleba localiza-se em um território distante, gerando, assim, uma dependência de transportes terrestres e dificuldades no acesso (BARNES, 2004 e 2006).

Outra tentativa para esses conflitos territoriais foi a criação de um termo de compromisso que garantia às populações tradicionais o direito de manter as condições de vida existentes na área de uma UC de proteção integral. Para isso, foi preciso estabelecer algumas normas e ações específicas como forma de compatibilizar a presença humana com os objetivos do parque (BARNES, 2004 e 2006).

\section{Conclusões}

A sobreposição entre unidades de conservação é uma realidade cada vez mais evidente e tem ocupado espaço nas discussões de diversos setores da sociedade na busca por uma solução para esse impasse.

Um dos casos mais emblemáticos trata-se de unidades de 
conservação de proteção integral ocupando o mesmo território de terras indígenas. Em uma ponta tem o Sistema Nacional de Unidades de Conservação (SNUC), que restringe a permanência de qualquer comunidade, tradicional ou não, nesses espaços, no outro extremo da equação estão as populações indígenas que desejam conservar as suas culturas centenárias.

Em uma disputa conceitual e filosófica, o que tem mais peso: a diversidade cultural ou a biológica? É possível escolher uma em detrimento da outra? Argumentos que reforçam o coro de um lado e de outro não faltam. Há dezenas de estudos que discorrem sobre a importância de se manter porções de terra totalmente preservadas, como grandes santuários da biodiversidade, intocáveis. Há tantos outros que contestam esses dizeres, que afirmam que é possível e viável a presença humana nesses locais, inclusive de forma harmônica.

Mas e perante o direito, quem de fato ganharia a disputa pela posse desses territórios? Ao usar-se o termo "disputa", automaticamente a mente separa os envolvidos em vencedor e perdedor, culpado e inocente, e é exatamente nesse ponto em que se encontra o grande equívoco envolvendo a sobreposição de terras indígenas e unidades de conservação.

Os dois lados estão amparados legalmente; mais que isso, ambos os envolvidos querem exatamente a proteção da floresta, querem a conservação de tal espaço. Assim, não há lados contrários, existem, contudo, e sobretudo, um emaranhado de questões burocráticas, que quando vencidas podem resultar em excelentes casos de sucesso.

Considerando, então, o exposto acima, e partindo do pressuposto de que unidades de conservação e terras indígenas foram criadas pelo mesmo motivo, um caminho possível a trilhar nesses locais seria a gestão compartilhada dessas áreas.

Uma característica marcante da sociedade ocidental de ascendência europeia é querer impor os seus gostos, sua cultura, sua visão e percepção das coisas a outras populações. A história recente está repleta de exemplos, foi assim com a chegada dos portugueses em terras brasileiras: ao se depararem com os índios que aqui viviam, despejaram os seus saberes e desconsideram qualquer conhecimento por parte dos indígenas. E talvez esse fato ainda se reflita nas nossas 
atitudes, por que um zoneamento que é realizado por uma equipe multidisciplinar de alguma agência ou órgão governamental é considerado como verdade absoluta e as divisões realizadas pelos indígenas não são sequer consideradas?

De uma forma clara, a questão é bem simples: é necessário considerar os conhecimentos dos índios. Há nessa cultura um saber popular que, aliado aos conhecimentos científicos, pode trazer benefícios para a conservação da biodiversidade e para o patrimônio cultural indígena.

\section{Referências bibliográficas}

ABIRACHED, Carlos Felipe de Andrade; BRASIL, Daniel; SHIRAISHI, Juliana Costa. Áreas Protegidas e Populações Tradicionais: Conflitos e Soluções. In: V ENCONTRO NACIONAL DA ANPPAS, 2010, Florianópolis. Anais... Florianópolis: UFSC, 2010. p. $1-20$.

BARNES, Eduardo Vieira. O Conselho Consultivo do Parque Nacional da Serra do Divisor: espaço público e espaços territoriais protegidos. In: FANY, Ricardo (Org.). Terras Indígenas e Unidades de Conservação da Natureza: o desafio das sobreposições. São Paulo: Instituto Socioambiental, 2004. p. 457-463.

O Conselho do Parque Nacional da Serra do Divisor: rituais políticos, (sobre) posições e representações territoriais. 2006. 252 f. Dissertação (Mestrado em Antropologia Social) - PPGAS, UNB, Brasília, [2006].

BRASIL. Constituição Federal 1988. Capítulo VIII - Dos índios (Arts. 231 e 232). Brasília, DF, 1988.

Decreto no 97.839, de 16 de junho de 1989. Cria o Parque Nacional da Serra do Divisor. Brasília, DF, 1989.

Lei $\mathbf{n}^{\circ}$ 9.985, de 18 de julho de 2000. Regulamenta o art. 225, $\S 1^{\circ}$, incisos I, II, III e VII da Constituição Federal, institui o Sistema Nacional de Unidades de Conservação da Natureza e dá outras providências. Diário Oficial [da] República Federativa do Brasil. Brasília, DF, 2000.

Decreto $\mathbf{n}^{\circ}$ 4.340, de 22 de agosto de 2002. Regulamente artigos da Lei $n^{\circ}$ 9.985, de 18 de julho de 2000 que dispõe sobre o Sistema Nacional de Unidades de Conservação da Natureza - SNUC, e dá outras providências. Brasília, DF, 2002.

Decreto no 5758, de 13 de abril de 2006. Institui o Plano Estratégico Nacional 
de Áreas Protegidas - PNAP, seus princípios, diretrizes, objetivos e estratégias, e dá outras providências. Brasília, DF, 2006.

CORREIA, Cloude de Souza. O Parque Nacional da Serra do Divisor e as Terras Indígenas Nawa e Nukini. In: FANY, Ricardo (Org.). Terras Indígenas e Unidades de Conservação da Natureza: o desafio das sobreposições. São Paulo: Instituto Socioambiental, 2004. p. 449-453.

Etnozoneamento, etnomapeamento e diagnóstico etnoambiental: representações cartográficas e gestão territorial em Terras Indígenas no estado do Acre. 2007. 431 f. Tese (Doutorado em Antropologia Social) - PPGAS, UNB, Brasília, [2007].

DIEGUES, Antonio Carlos. O mito moderno da natureza intocada. Hucitec: São Paulo, 2001.

FUNDAÇÃO NACIONAL DO ÍNDIO. Demarcação de terras indígenas. 2016. Disponível em: http://www.funai.gov.br/index.php/2014-02-07-13-24-32?start=2\# Acesso em: 03 abr. 2016.

ICMBIO. Mapas ICMBIO. Brasília: MMA, 2015. Disponível em: http://mapas.icmbio.gov.br/i3geo/icmbio/mapa/externo/home.html?n1mbqv3e9gem7kg varev9ip6n3. Acesso em: 23 mai. 2015.

IBAMA. Plano de Manejo do Parque Nacional da Serra do Divisor. Brasília: IBAMA, 1998.

1999.

Plano de Manejo do Parque Nacional do Monte Roraima. Brasília, DF,

INSTITUTO SOCIOAMBIENTAL. Nukini: população, localização e ambiente. In: Povos Indígenas no Brasil: N.d. Disponível em: http://pib.socioambiental.org/pt/povo/nukini/824. Acesso em: 13 mai. 2016.

Terras Indígenas e Unidades de Conservação da natureza: o desafio das sobreposições. ISA: São Paulo, 2004.

LAURIOLA, Vincenzo. Parque Nacional? Kaané! Os índios dizem não à implementação do Parque Nacional do Monte Roraima. In: FANY, Ricardo (Org.). Terras Indígenas e Unidades de Conservação da Natureza: o desafio das sobreposições. São Paulo: Instituto Socioambiental, 2004. p. 422-431.

MACKINNON, John et al. Manejo de áreas protegidas en los trópicos. México: Difel, 1990.

MINISTÉRIO DO MEIO AMBIENTE. Biodiversidade e Comunidades Tradicionais no Brasil. São Paulo: MMA, 1999. 
OLIVEIRA, Eliana Costa; MARTINI, Andréa; LESSIN, Leonardo. A trajetória de Pamani Pixtri Nukini na educação acreana. Revista VITAS, Rio de Janeiro, v. 2, n. 5, p. 1-17, dez. 2012.

RODRIGUES, Marco Aurélio. Ocupação humana e conservação no Parque Nacional da Serra do Divisor (PNSD), Alto Juruá- Acre. 2006. 143 f. Dissertação (Mestrado em Geografia) - PPGG, UNICAMP, Campinas, [2006].

RUFINO, Marcos Pereira. O fio da meada. In: FANY, Ricardo (Org.). Terras Indígenas e Unidades de Conservação da Natureza: o desafio das sobreposições. São Paulo: Instituto Socioambiental, 2004. p. 417-420.

SCARDUA, Fernando Paiva. Manejo sustentável no Parna do Monte Roraima e na TI Raposa/Serra do Sol. In: FANY, Ricardo (Org.). Terras Indígenas e Unidades de Conservação da Natureza: o desafio das sobreposições. São Paulo: Instituto Socioambiental, 2004. p. 432-435.

VELÁSQUEZ, Cristina; GARCIA, Uirá Felippe. A Serra do Divisor e o problema das divisões. In: FANY, Ricardo (Org.). Terras Indígenas e Unidades de Conservação da Natureza: o desafio das sobreposições. São Paulo: Instituto Socioambiental, 2004. p. 445-448.

Recebido em: 07/10/2015 * Aprovado em: 16/05/2016 * Publicado em: 30/06/2016 